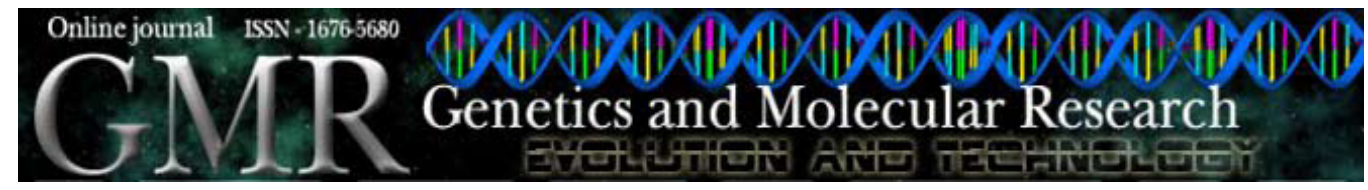

\title{
Differences between the quality of strawberries (Fragaria $x$ ananassa) pollinated by the stingless bees Scaptotrigona aff. depilis and Nannotrigona testaceicornis
}

\author{
A.C. Roselino, S.B. Santos, M. Hrncir and L.R. Bego \\ Departamento de Biologia, Universidade de São Paulo, \\ Ribeirão Preto, SP, Brasil \\ Corresponding author: A.C. Roselino \\ E-mail: acr@aluno.ffclrp.usp.br
}

Genet. Mol. Res. 8 (2): 539-545 (2009)

Received December 12, 2008

Accepted January 26, 2009

Published May 12, 2009

\begin{abstract}
We investigated the success of two stingless bee species in pollinating strawberries in greenhouses. Three greenhouses and one open field area were used; one greenhouse had only strawberry plants (control), another (G1) had three colonies of Scaptotrigona aff. depilis and another (G2) had three colonies of Nannotrigona testaceicornis. In the open field area, the flowers could be visited by any bee. The total production of fruits was counted and a random sample $(\mathrm{N}=100)$ from each area was used to measure weight, length, circumference, and achenes number $(\mathrm{N}=5)$. The percentages of deformed strawberries were: $23 \%$ (no bees); $2 \%$ (greenhouses with bees) and $13 \%$ (open field). The strawberries from the greenhouse with $N$. testaceicornis and the open field were heavier than those from the greenhouses with no bees and with $S$. depilis. The fruit circumference was largest in the greenhouses with
\end{abstract}


bees. The achenes number did not differ among the experimental areas. The strawberries produced in the greenhouses with stingless bees had more quality and greater commercial value than the fruits produced in the open field area and the greenhouse without bees. We conclude that stingless bees are efficient pollinators of strawberry flowers cultivated in greenhouses.

Key words: Stingless bees; Pollination; Greenhouse; Strawberry

\section{INTRODUCTION}

Pollination, the transfer of pollen grains among reproductive parts of flower, is a natural phenomenon that is necessary for the reproduction of many plants. When the reproductive structures are on the same flower, self-pollination can occur. However, this is not a common phenomenon (Free, 1993). Natural mechanisms such as temporal differences between the maturation of sexual parts avoid self-pollination and thus, favor the cross-pollination (Huertas and Silveira, 1983; Jolivet, 1992). Several physiological events of angiosperm's development like changes in the pigmentation, senescence and abscission flower organs, growth and development of the ovaries are controlled by pollination, promoting the reproductive success of plants (O'Neill, 1997). The development of strawberry fruit (Fragaria x ananassa) is controlled by achenes (Nitsch, 1950). The achenes need to be fertilized in order to supply auxin, a vegetal hormone, which insures the plant growth. If, the flowers are completely fertilized, they generate well-formed fruits, which mature in a short time (Nitsch, 1950; Chagnon et al., 1989; Free, 1993). This study was performed to investigate the production and the quality of strawberries pollinated by the stingless bees Scaptotrigona aff. depilis Moure and Nannotrigona testaceicornis Lepeletier in greenhouses.

\section{MATERIAL AND METHODS}

The experiments were carried out in September and October 2003 on the campus of the University of São Paulo in Ribeirão Preto, Brazil. As experimental areas, we used three greenhouses and one open field area (each measuring $87.5 \mathrm{~m}^{2}$ ). In each area, strawberries Fragaria $x$ ananassa Ducke (variety Camarosa) were planted in the holes of plastic bands (70 $\mathrm{cm}$ width $\times 12 \mathrm{~m}$ length). All areas had 6 row plants, irrigated by dripping and manured with CRISTASSOL ${ }^{\circledR}$ 6:12:36 (700 g/500 mL water). To avoid plagues, solution of tobacco $\left(\right.$ Fumy $\left.^{\circledR}\right)$ in water was dispersed over the plants, once a week. One greenhouse had only plants (Gc) and was used as control. In two greenhouses (G1, G2), pollen transfer between different strawberry flowers was facilitated by using stingless bees as potential pollinating agents. Greenhouse 1 was supplied with 3 hives of Scaptotrigona aff. depilis, G2 with 3 hives of Nannotrigona testaceicornis. The third greenhouse (Gc) did not house insect pollinators. Fertilization of flowers could only occur through cross-pollination. The flowers in the open field area $(\mathrm{Oa})$, on the other hand, could be visited by any free-flying bee. A sample of these bees was collected for further identification. Other plant visitors, such as lepdopterans and ants, were not taken into account because did not show pollina- 
tor behavior. The number of plants differed slightly between the greenhouse (Gc: 182; G1: 166, G2: 164, and Oa: 191). The number of flowers was counted once daily, at 8:00 am. Between 8:00 and 17:00, we counted the total amount of flower visits for 15 min per hour, using a manual counter (NUMBER-MATIC ${ }^{\circledR}$ ). The flower visiting time of 100 individuals per specie was recorded with a chronometer to the nearest second. The total production of strawberries was counted in each experimental area. The strawberries that did not show "commercial shape" were considered deformed. From a random sample of 100 fruits per experimental area, we measured the individual weight (g) (Precision Balance MARTE ${ }^{\circledR}$ ), the length and the biggest circumference $(\mathrm{cm})$. The number of fecundated achenes was verified in five strawberries from each experimental area. For this, the achenes were removed with entomological tweezers and put into a cup of water. Those achenes that sank in the water were considered fecundated (Thompson, 1971). The measures for the quality of the strawberries (weight and size) were compared among the different experimental areas using ANOVA, the Tukey test and the Kruskal-Wallis test (Dunn's post hoc pair wise comparison). Differences in total fruit production and in the percentage of deformed fruits between the areas were investigated using the chi-square test. For the statistical analyses, we used the Statistical Software for Professionals (STATA).

\section{RESULTS}

During our study, the strawberry flowers typically opened at 7:00 am and started wilting at 5:00 pm. The foraging activity of both bees species, Scaptotrigona aff. depilis and Nannotrigona testaceicornis, fit well into this temporal window of flowering. The bees started to visit the flowers at 9:00 am and stopped at 4:00 pm. The peak foraging activity differed slightly between $S$. aff. depilis and $N$. testaceicornis. The bees in G1, S. aff. depilis, had their peak activity between 1:00 am and 2:00 pm, whereas the bees in G2, $N$. testaceicornis, had the highest foraging activity between 10:00 am and 12:00 am. The average number of flowers varied among the experimental areas (Gc: $42 \pm 12.5$; G1: 57.9 $\pm 18 ; \mathrm{G} 2: 67.6 \pm 27.4$, and Oa: $79.8 \pm 22.9)(\mathrm{P}<0.05$; one-way ANOVA; Tukey test $)$. The strawberry flowers lived for an average of $2.5 \pm 0.6$ days $(\mathrm{N}=40)$. The bees in the greenhouses and in the open area visited the flowers even when they lost their petals, and the color of anthers changed from yellow to brown. Only after the stigmata turned dark, the bees were no longer attracted to the flowers. We observed differences in flower visitation behavior between the two bee species. S. aff. depilis walked upon the stigmata of the flowers, and $N$. testaceicornis walked around the stigmata, close to the anthers. The time spent on the flowers was statistically different between the stingless bees. $S$. aff. depilis spent an average $29.2 \pm 24.7 \mathrm{~s}$ and $N$. testaceicornis spent an average $73.8 \pm 58.6 \mathrm{~s}$ for each flower visit ( $\mathrm{P}<0.05$; ANOVA; Kruskal-Wallis test). We found significant differences in the daily number of flower visits by bees between the different experimental areas. During our daily observation period (15 min per hour between 8:00 am and 5:00 pm) we counted 45.5 \pm 56.2 visits by $S$. aff. depilis (G1), $76.4 \pm 53.6$ visits by $N$. testaceicornis (G2) and 37 \pm 19.2 visits by social bees (Trigona recursa, Paratrigona lineata and N. testaceicornis) in the $\mathrm{Oa}(\mathrm{P}<0.05$; ANOVA). Due to the high variability in the number of bee visits, the differences between the experimental treatments was significant only between $\mathrm{G} 1$ and $\mathrm{Oa}$ $(\mathrm{P}<0.05$; Tukey test) (Figure 1). 


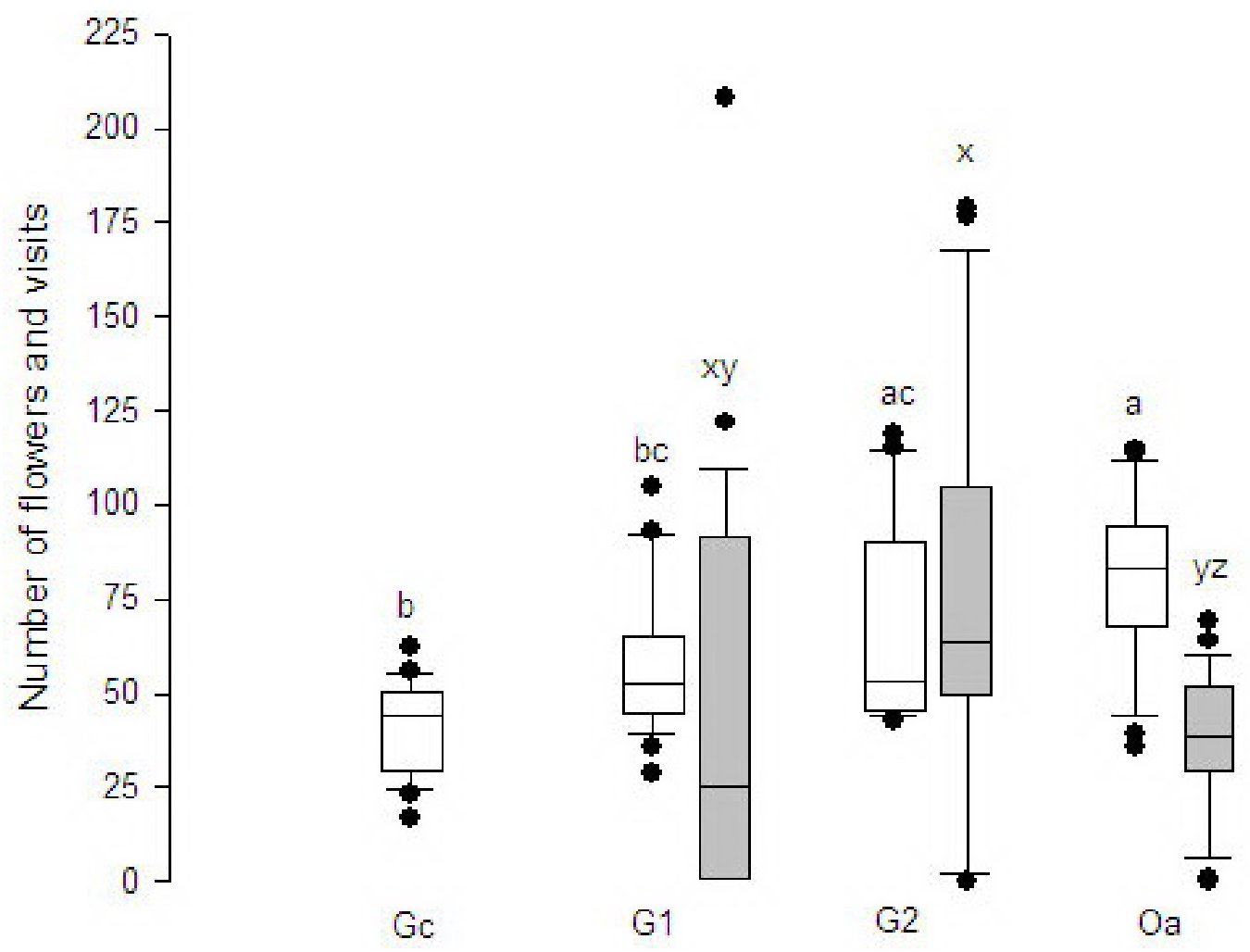

Figure 1. Box plots showing the number of strawberry (Fragaria x ananassa) flowers (open boxes) and number of flower visits by bees (shaded boxes) in Gc (greenhouse control), G1 (greenhouse with Scaptotrigona aff. depilis), G2 (greenhouse with Nannotrigona testaceicornis), and in Oa (open field area). P $<0.05$; one-way ANOVA; Tukey test. Different letters indicate significant differences between the groups.

As expected, the experimental areas with bee pollination yielded a higher total amount of strawberries than the control greenhouse (total strawberry production: Gc: 438; G1: 743, G2: 847, and Oa: 775; $\mathrm{P}<0.001$; chi-square test $=139.45$; d.f. $=3$ ). Also, the percentage of deformed strawberries was lower when strawberries had been bee pollinated (deformed strawberries from a sample of 100 fruits (Gc: 23\%; G1:2\%; G2: 2\%, and Oa: 13\%; P $<0.001$; chi-square test $=25.44$; d.f. $=3$ ). There was no difference in the number of achenes of strawberries produced between the different experimental areas (Gc: $202.4 \pm 91.6$; G1: $284 \pm 51.1$; G2: $370.8 \pm 166$, and Oa: $253.2 \pm 53.9 ; \mathrm{P}<0.05$; ANOVA; Kruskal-Wallis test). Concerning fruit quality parameters (weight, length and circumference), we found significant differences among the different experimental areas. In general, fruits collected in G2 were heavier and bigger than fruits in the other experimental areas (weight: Gc: $10.6 \pm 4.5 ; \mathrm{G} 1: 11.2 \pm 4.0 ; \mathrm{G} 2$ : $12.8 \pm 3.6$; Oa: $11.5 \pm 2.8$ (Figure 2) - length: Gc: $5.5 \pm 5.5$; G1: $4.8 \pm 0.8 ;$ G2: $5.0 \pm 0.9$; Oa: $4.7 \pm 0.7$ - circumference: Gc: $8.3 \pm 1.2$; G1: $9.0 \pm 1.1$; G2: $9.5 \pm 1.0$; Oa: $8.8 \pm 0.8(\mathrm{P}<0.05$; ANOVA; Kruskal-Wallis test) (Figure 3). 


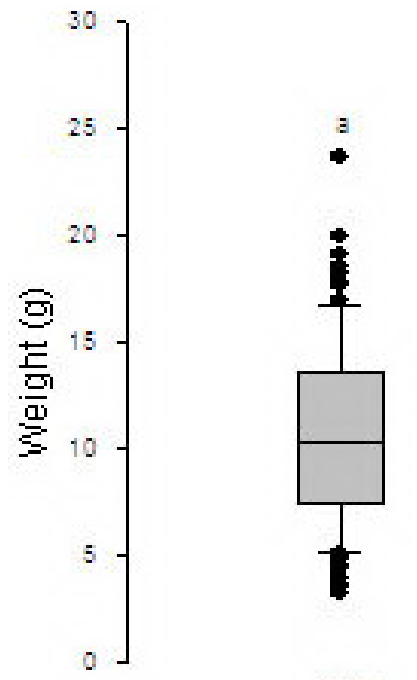

$$
\text { G0 } \quad \text { G1 }
$$

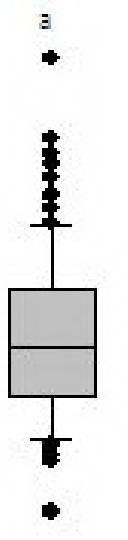

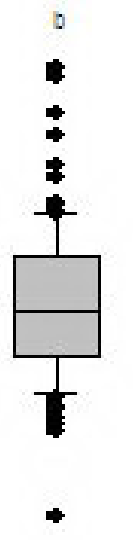

Q2

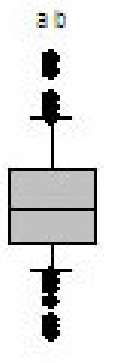

$0 \mathrm{a}$

Figure 2. Box plots showing the weight of strawberries (Fragaria x ananassa), N=100, from Gc (greenhouse control), G1 (greenhouse with Scaptotrigona aff. depilis), G2 (greenhouse with Nannotrigona testaceicornis), and Oa (open field area). $\mathrm{P}<0.05$; ANOVA; Kruskal-Wallis test. Different letters indicate significant differences between experimental areas.

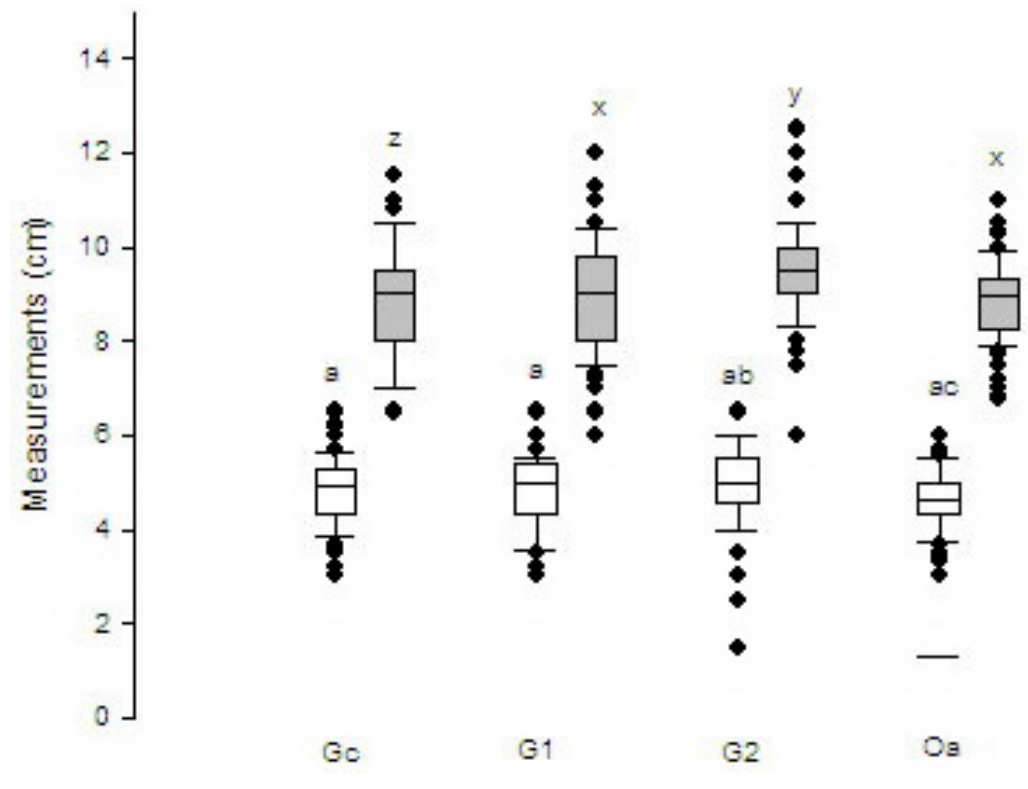

Figure. 3. Box plots showing the length (open boxes) and circumference (shaded boxes) of strawberries (Fragaria $x$ ananassa), $\mathrm{N}=100$, from Gc (greenhouse control), G1 (greenhouse with Scaptotrigona aff. depilis), G2 (greenhouse with Nannotrigona testaceicornis), and Oa (open field area). P < 0.05; ANOVA; Kruskal-Wallis test. Different letters indicate significant differences between experimental areas. 


\section{DISCUSSION}

Strawberry plants have hermaphrodite flowers. However, the female reproductive organ becomes receptive before the male element, the pollen, in the same flower is available. This feature of the strawberry flowers favors cross-pollination. The fertilization of strawberry flowers has a direct influence on the quality of the fruits, because the amount of fertilized achenes determines the amount of auxin within a fruit during its development. Auxin, furthermore, is responsible for the growth of the fruits (Nitsch, 1950). Mobile pollinating agents like bees, which facilitate cross-pollination, are therefore essential for a commercially successful development of strawberry fruits.

In the present study, we demonstrate that strawberries deriving from cross-pollination by bees had a better quality than fruits deriving from self-pollination (control greenhouse). In all experimental areas (G1, G2, Oa) in which the strawberry flowers were visited by bees, the fruit-set was bigger, and the strawberries were bigger and heavier (Figures 2 and 3). Similar results were obtained by Malagodi-Braga (2002) who used Tetragonisca angustula as pollinating agent. The author demonstrated that fruits deriving from flowers pollinated by these stingless bees had a higher quality than strawberries deriving from self-pollination.

Despite the fact that Apis mellifera is considered one of the most important pollinators of strawberries (Goodman and Oldroyd, 1988; Oliveira et al., 2001), we did not observed this bee visiting the flowers in our open field area, even though a big apiary was located close to the experimental area. The pollinators identified on the strawberry flowers were other species of stingless bees that naturally occurred in this area: Trigona recursa, Paratrigona lineata and Nannotrigona testaceicornis. The presence of Nannotrigona testaceicornis on flower in the open area indicates that this bee species is naturally attracted to strawberry flowers and therefore, is an adequate pollinating agent of strawberries in greenhouse. This complies with the findings of Maeta et al. (1992) who showed the pollination success of N. testaceicornis in greenhouses. The authors demonstrated that flowers need to be visited only four times by individuals of this specie to develop well-formed fruit.

The efficiency of bees as pollinators of strawberry flowers has already repeatedly been demonstrated (McGregor, 1976; Mota, 1998). Yet, differences in the fruit outcome (quantity and quality) due to the use of different bee species under the same conditions have so far remained little investigated.

In Japan, Kukutani et al. (1993) compared the efficiency of the stingless bee Trigona minangkabau as pollinator of greenhouse strawberries with that of Apis mellifera. The authors demonstrated that the stingless bees pollinate strawberries as well as honeybees, but that more individuals of $T$. minangkabau are necessary to achieve a similar pollination success (determined by the proportion of deformed fruits) as the A. mellifera. Chang et al. (2001) compared the success in pollinating strawberry flowers in greenhouses of two species of the genus Apis, A. mellifera and A. cerana. They demonstrated that A. mellifera was more efficient than $A$. cerana. All fruits deriving from flowers pollinated by $A$. mellifera were well-formed, whereas those pollinated by A. cerana showed a proportion of deformed fruits between 2 and $45 \%$.

In the present study, we compared the pollination success of two stingless bees species. Strawberries pollinated by $N$. testaceicornis were heavier and bigger than those pollinated by $S$. aff. depilis. These differences might be due to the behavioral differences during the collection of pollen and nectar between the two bee species. N. testaceicornis spent longer time on the flowers than Scaptotrigona aff. depilis to collect the pollen and the nectar. This temporal differ- 
ence between the bee species is probably due to the smaller size of $N$. testaceicornis workers in comparison to Scaptotrigona aff. depilis. More importantly, however, the way the bees moved on the flower during their collecting activity apparently determined the shape of the fruits. The behavior of Scaptotrigona aff. depilis favored an equal pollination of all stigmas. Therefore, the fruits from G1 present an excellent commercial shape and a massive interior. The behavior of $N$. testaceicornis, on the other hand, favored the pollination of the lateral stigmas over the central stigmas. The fruits deriving from flowers pollinated by these bees, therefore, presented a large circumference and the interior strawberry in some cases was hollow. Although strawberry plants in the open field area produced more flowers than those in the greenhouses, we found the highest production of strawberry fruit in G2 with $N$. testaceicornis.

Primack (1987) hypothesized a relationship between the number of flowers and the amount of the produced fruits. Those plants that produce a small amount of flowers consequently will produce a small amount of fruits. These fruits, however, should develop better because the energy offered by the plants is channeled towards them. Hence, the smaller availability of flowers in the greenhouses 1 and 2 in relation to the open field area could have favored the development of fruit resulting in a low percentage of deformed strawberries.

\section{ACKNOWLEDGMENTS}

Research supported by FAPESP, CAPES and CNPq. We thank Sidnei Mateus for his unfailing help with the maintenance of the colonies.

\section{REFERENCES}

Chagnon M, Gingras J and Oliveira D (1989). Pollination rate of strawberries. J. Econ. Ecol. 82: 1350-1353.

Chang DY, Lee MY and Mah Y (2001). Pollination on strawberry in the vinyl house by Apis mellifera L. and A. cerana Fab. Acta Hort. 561: 252-262. Available at [http://www.actahort.org/books/561/561_38.htm]. Accessed July 13, 2007.

Free JB (1993). Insect Pollination of Crops. Academic Press, London.

Goodman RD and Oldroyd BP (1988). Honeybee pollination of strawberries (Fragaria x ananassa Duchesne). Aust. J. Exp. Agric. 28: 435-438.

Huertas AAG and Silveira FA (1983). A utilização das abelhas na polinização de plantas cultivadas. Inf. Agropec. 9: 19-26. Jolivet P (1992). Insects and Plants: Parallel Evolution and Adaptations. 2nd edn. Ross. H. Arnett Jr., Florida, 126-158.

Kukutani T, Inoue T and Maeta Y (1993). Pollination of strawberry by the stingless bee, Trigona minangkabao, and the Honeybee, Apis mellifera: an experimental study of fertilization efficience. Res. Pop. Ecol. 35: 95-111.

Maeta Y, Tezuka T, Nadano H and Suzuki K (1992). Utilization of the Brazilian stingless bee, Nannotrigona testaceicornis, as a pollinator of strawberries. Honeybee Sci. 13: 71-78.

Malagodi-Braga KS (2002). Estudo de Agentes Polinizadores em Cultura de Morango (Fragaria x ananassa Duch. Rosácea). Doctoral thesis, Instituto de Biociências, São Paulo.

McGregor SE (1976). Insect Pollination of Cultivated Crop Plants. Agricultural Research Service, Tucson.

Mota MOS (1998). Polinização Entomófila e Produção de Frutos e Sementes nas Culturas de Morango (Fragaria $\mathrm{x}$ ananassa D.), Pêssego (Prunus persica L.) e Camomila (Chamomilla recutita L.). Undergraduate thesis, UNESP, Jaboticabal, São Paulo.

Nitsch JP (1950). Growth and morphogenesis of the strawberry as related to auxin. Am. J. Bot. 37: 211-215.

O'Neill SD (1997). Pollination regulation of flower development. Annu. Rev. Plant Physiol Plant Mol. Biol. 48: 547-574.

Oliveira D, Savoie L and Vincent C (2001). Pollinators of cultivated strawberry in Québec. In: ISHS Acta Horticulturae 561: VIII International Symposium on Pollination - Pollination: Integrator of Crops and Native Plant Systems. Available at [http://www.actahort.org/books/561/561_38.htm]. Accessed July 13, 2007.

Primack RB (1987). Relationships among flowers, fruits, and seeds. Ann. Rev. Ecol. Syst. 18: 409-430.

Thompson PA (1971). Environmental effects on pollination and receptacle development in strawberry. J. Hortic. Sci. 46: 1-12. 